Helga Scholten

\title{
Die Sophistik
}





\section{Helga Scholten}

Die Sophistik

Eine Bedrohung

für die Religion und Politik

der Polis?

Akademie Verlag 


\begin{abstract}
Als Habilitationsschrift auf Empfehlung des Fachbereichs 1: Geistes- und Gesellschaftswissenschaften der Universität Duisburg gedruckt mit Unterstützung der Deutschen Forschungsgemeinschaft
\end{abstract}

ISBN 3-05-003729-6

(c) Akademie Verlag GmbH, Berlin 2003

Das eingesetzte Papier ist alterungsbeständig nach DIN/ISO 9706

Alle Rechte, insbesondere die der Übersetzung in andere Sprachen, vorbehalten.

Kein Teil dieses Buches darf ohne schriftliche Genehmigung des Verlages in irgend einer Form - durch Photokopien, Mikroverfilmung oder irgendein anderes Verfahren - reproduziert oder in eine andere von Maschinen, insbesondere von Datenverarbeitungsmaschinen, verwendbare Sprache übertragen oder übersetzt werden.

Einbandgestaltung: Dietrich Otte

Druck: Druckhaus ,Thomas Müntzer“, Bad Langensalza

Bindung: Norbert Klotz, Jettingen-Scheppach

Gedruckt in Deutschland 